\title{
Morphological bactericidal fast-acting effects of peracetic acid, a high-level disinfectant, against Staphylococcus aureus and Pseudomonas aeruginosa biofilms in tubing
}

\author{
T. Chino ${ }^{1,2^{*}}$, Y. Nukui ${ }^{1}$, Y. Morishita ${ }^{3}$ and K. Moriya ${ }^{4}$
}

\begin{abstract}
Background: The bactericidal effect of disinfectants against biofilms is essential to reduce potential endoscopy-related infections caused by contamination. Here, we investigated the bactericidal effect of a high-level disinfectant, peracetic acid (PAA), against Staphylococcus aureus and Pseudomonas aeruginosa biofilm models in vitro.

Methods: S. aureus and P. aeruginosa biofilms were cultured at $35^{\circ} \mathrm{C}$ for 7 days with catheter tubes. The following high-level disinfectants (HLDs) were tested: 0.3\% PAA, 0.55\% ortho-phthalaldehyde (OPA), and 2.0\% alkaline-buffered glutaraldehyde (GA). Biofilms were exposed to these agents for 1-60 min and observed after 5 min and 30 min by transmission and scanning electron microscopy. A Student's $t$ test was performed to compare the exposure time required for bactericidal effectiveness of the disinfectants.

Results: PAA and GA were active within 1 min and 5 min, respectively, against $S$. aureus and P. aeruginosa biofilms. OPA took longer than $10 \mathrm{~min}$ and $30 \mathrm{~min}$ to act against $S$. aureus and $P$. aeruginosa biofilms, respectively $(p<0.01)$. Treatment with PAA elicited changes in cell shape after $5 \mathrm{~min}$ and structural damage after $30 \mathrm{~min}$.

Conclusions: Amongst the HLDs investigated, PAA elicited the most rapid bactericidal effects against both biofilms. Additionally, treatment with PAA induced morphological alterations in the in vitro biofilm models, suggesting that PAA exerts fast-acting bactericidal effects against biofilms associated with endoscopy-related infections. These findings indicate that the exposure time for bactericidal effectiveness of HLDs for endoscope reprocessing in healthcare settings should be reconsidered.
\end{abstract}

Keywords: Peracetic acid, Staphylococcus aureus biofilm, Pseudomonas aeruginosa biofilm, Bactericidal effectiveness, Exposure time, Electron microscopy

\section{Background}

Biofilms protect bacteria from stress or stimuli by providing a thick layer of extracellular proteins [1]. Biofilm in bacterial communities is formed through initial and irreversible attachment, microcolony formation, biofilm maturation, and biofilm dispersion [2]. Biofilm matrix

\footnotetext{
* Correspondence: takashi.chino@fujifilm.com

'Department of Infection Control and Prevention, Medical Hospital, Tokyo Medical and Dental University, Tokyo, Japan

${ }^{2}$ Clinical Development Department, FUJIFILM Pharma Co., Ltd, 26-30,

Nishiazabu 2-Chome, Tokyo, Japan

Full list of author information is available at the end of the article
}

comprises polysaccharides, proteins, and nucleic acids that can be dissolved by enzymatic degradation [3]. Proteinaceous components, such as the non-ribosomally generated peptide aureusimine (phevalin) in Staphylococcus aureus [4] and three exopolysaccharides (Psl, Pel, and alginate) in Pseudomonas aeruginosa [2, 3], play important roles in biofilm structural maintenance and are highly resistant to antibiotics and disinfectants. The biofilm-forming bacteria $S$. aureus and $P$. aeruginosa are major opportunistic pathogens implicated in hospitalacquired infections; these bacteria are additionally 
known to promote the spread of chronic diseases, including osteomyelitis and endocarditis, contaminate medical device implants, and persist in lung cystic fibrosis [2, 4]. Specifically, endoscopy-related infections caused by biofilm adhesion within the narrow luminal cavities of endoscope channels are attributed to inadequate cleaning routines and ineffective disinfection procedures $[5,6]$ despite adherence to guideline recommendations $[7,8]$. These are often reported in conjunction with pseudooutbreaks of biofilm-producing bacteria [9-11]. Additionally, biofilms are recalcitrant to endoscope reprocessing, resulting in infection by $P$. aeruginosa and Mycobacterium chelonae isolates, such as those with high resistance to glutaraldehyde (GA) [12, 13].

In order to effectively remove biofilms from endoscope channels, automated endoscope reprocessors (AERs) have become widespread in Japan, particularly in combination with novel high-level disinfectants (HLDs) such as peracetic acid (PAA) and ortho-phthalaldehyde (OPA); these broad-spectrum disinfectants have replaced GA [14-16]. The exposure time required for bactericidal effectiveness of HLDs, according to current Japanese multisociety guides on reprocessing flexible GI endoscopes, is routinely recommended as $5 \mathrm{~min}$ for $0.3 \%$ PAA, $10 \mathrm{~min}$ for $0.55 \% \mathrm{OPA}$, and $10 \mathrm{~min}$ for $2.0 \% \mathrm{GA}$. Other guidelines state that this duration is dependent on the concentration of the specific HLDs [17-19]. In addition, the ability of OPA to fix stains (bacterial proteins or biofilms) onto materials $[20,21]$ and involvement of efflux as a GA resistance mechanism in $P$. fluorescens and P. aeruginosa biofilms [22] have been reported; however, the mechanism associated with PAA activity, specifically its ability to fix or remove biofilms from materials, is not completely understood. Furthermore, to date, comparison of the exposure times for bactericidal effectiveness of PAA and OPA against biofilms, under the same conditions, has not been attempted.

Here, we investigated the exposure time for bactericidal effectiveness of three HLDs used in Japan, using in vitro biofilm models. The study aimed to examine AMR outcomes associated with biofilms, including in drugresistant strains, and to visualize the bacterial inner-cell and outer-surface morphological structures by electron microscopy. The findings offer novel insights into PAA activity against biofilms.

\section{Methods}

\section{Bacterial strains and biofilm growth conditions}

Strains used in this study included $S$. aureus isolates ATCC 29213, ATCC 25923, 209P, TT-UA-1, MK99-1, MK99-2, MK99-3, MK99-4, MK99-5, MK99-6, MK99-7, and MK99-8; and P. aeruginosa isolates ATCC 33348, ATCC 27853, E7, 16-45, 10-49, 14-57, 27-08, 27-122, 31-56, 4-37, 4-6, and 1-95. Prior to use, strains were stored at $-80{ }^{\circ} \mathrm{C}$. All strains were first subcultured and then diluted to $10^{3}$ colony-forming units $(\mathrm{CFU}) / \mathrm{mL}$ in Mueller-Hinton broth (MHB; Difco, BD Biosciences, San Jose, CA, USA) for subsequent cultivation with catheter tubes at $35{ }^{\circ} \mathrm{C}$ in a horizontal shaking incubator. Each polyvinyl chloride catheter tube (diameter, $5 \mathrm{~mm}$; Terumo, Tokyo, Japan) was cut into 10-mm-long round slices and sterilized prior to biofilm growth. Mature biofilms were obtained after 7 days of incubation (data not shown) and initial inoculation of $1.5 \times 10^{8} \mathrm{CFU}$ to $5.0 \times 10^{8} \mathrm{CFU}$ per tube.

\section{Chemical disinfectant preparation}

Each disinfectant was diluted with sterile water according to manufacturers' instructions: $0.3 \%$ PAA $(6 \%$ Acecide; Saraya Co., Ltd., Osaka, Japan), 0.55\% OPA (undiluted Disopa; Johnson \& Johnson, Pittsburgh, PA, USA), $2.0 \%$ GA (20\% Sterihyde; Maruishi Pharmaceutical Co., Ltd., Osaka, Japan) for endoscopy HLD, or 0.1\% sodium hypochlorite solution $(\mathrm{NaClO} ; 1 \%$ Yakulax; Yakuhan Pharmaceutical Co., Ltd., Hokkaido, Japan); chlorine levels that are safe for environmental disinfection at comparable standard formulations were used. Sterile distilled water (SDW) was used as a positive control for diluted disinfectant testing.

\section{In vitro biofilm models}

Prior to disinfection, laboratory-grown mature biofilms accumulated in plastic tubing were transferred to $5-\mathrm{mL}$ sterile test tubes, followed by transfer of $2 \mathrm{~mL}$ of disinfectant into each test tube for gentle mixing. Test samples were exposed for $1,2,5,10,15,30$, and $60 \mathrm{~min}$; immediately after treatment, biofilms were carefully rinsed twice with phosphate-buffered saline (PBS; $\mathrm{pH}$ 7.4) to inactivate the drug and remove floating bacteria. The bactericidal effects were assessed after incubating each tubing sample at $35{ }^{\circ} \mathrm{C}$ for 2 days and visually determining the presence of a bacterial suspension. Bacterial growth was confirmed by agar-plate incubation. Every experiment included a positive control biofilm culture and non-inoculated MHB as a negative control, and was performed five times.

\section{Transmission electron microscopy (TEM)}

$S$. aureus 209P and P. aeruginosa E7 strains were selected for microscopic observation, because they produced more biofilm matrix than other cultures in this study. As previously described, biofilms were exposed to $0.3 \%$ PAA and $2.0 \%$ GA for 5 min and $30 \mathrm{~min}$. Immediately after treatment, $S$. aureus and $P$. aeruginosa biofilms were rinsed with $\mathrm{PBS}(\mathrm{pH} 7.4)$ and $0.1 \mathrm{M}$ cacodylic acid buffer solution ( $\mathrm{pH} 7.2$ ), respectively. Samples were fixed overnight with $2.5 \%$ electron microscope-grade GA and $0.1 \%$ uranium acetate, 
followed by fixation with $1.0 \%$ osmium tetroxide and $1.0 \%$ tryptophan for $5 \mathrm{~h}$. Samples were then washed with $0.1 \%$ tannic acid buffer, dehydrated in a graded ethanol series, and embedded in Epon 812 resin by polymerization at $60{ }^{\circ} \mathrm{C}$. Samples were cut with an ultra-microtome fitted with a glass knife, stained with $5.0 \%$ uranium acetate for $15 \mathrm{~min}$ and $0.1 \%$ lead citrate for $5 \mathrm{~min}$ at $20{ }^{\circ} \mathrm{C}$, coated with carbon, and observed under a JEM-1200EX TEM (Jeol Ltd., Tokyo, Japan) at $80 \mathrm{kV}$.

\section{Scanning electron microscopy (SEM)}

S. aureus 209P and P. aeruginosa E7 biofilms were prepared following the same protocol as described for TEM observation. Samples were fixed for $2 \mathrm{~h}$ at room temperature, first with $2.5 \%$ electron microscope-grade GA and then with $1.0 \%$ osmium tetroxide. Samples were then washed with $0.1 \%$ tannic acid buffer, dehydrated in a graded ethanol series, and dried in a critical point dryer with isoamyl acetate and carbon dioxide. Samples were set on a stand using carbon tape coated with platinum and observed under a S-4500 SEM (Hitachi,
Tokyo, Japan) at $15 \mathrm{kV}$ to $20 \mathrm{kV}$ (at least 10 fields/ biofilm).

\section{Statistical analysis}

Complete bactericidal activity was defined as the absence of bacterial suspensions in all five experiments for each exposure time. A Student's $t$ test was performed to compare exposure times for bactericidal effectiveness between disinfectants and the control. $P<0.05$ was considered significant, and the results were analyzed using Microsoft Excel (Microsoft, Co., Redmond, WA, USA).

\section{Results}

Biofilm resistance to disinfectants

The bactericidal effects of 0.3\% PAA, 0.55\% OPA, 2.0\% $\mathrm{GA}$, and $0.1 \% \mathrm{NaClO}$ against $12 \mathrm{~S}$. aureus and 12 P. aeruginosa biofilms accumulated on tubing for 7 days was tested. PAA showed the most rapid killing of all 24 strains (within $1 \mathrm{~min}$ ) (Fig. 1). In contrast, it took $5 \mathrm{~min}$ for $100 \%$ bactericidal activity to be achieved with GA, and $15 \mathrm{~min}$ ( $S$. aureus) and $60 \mathrm{~min}$ ( $P$. aeruginosa) with OPA. Compared with $\mathrm{NaClO}$, OPA was particularly

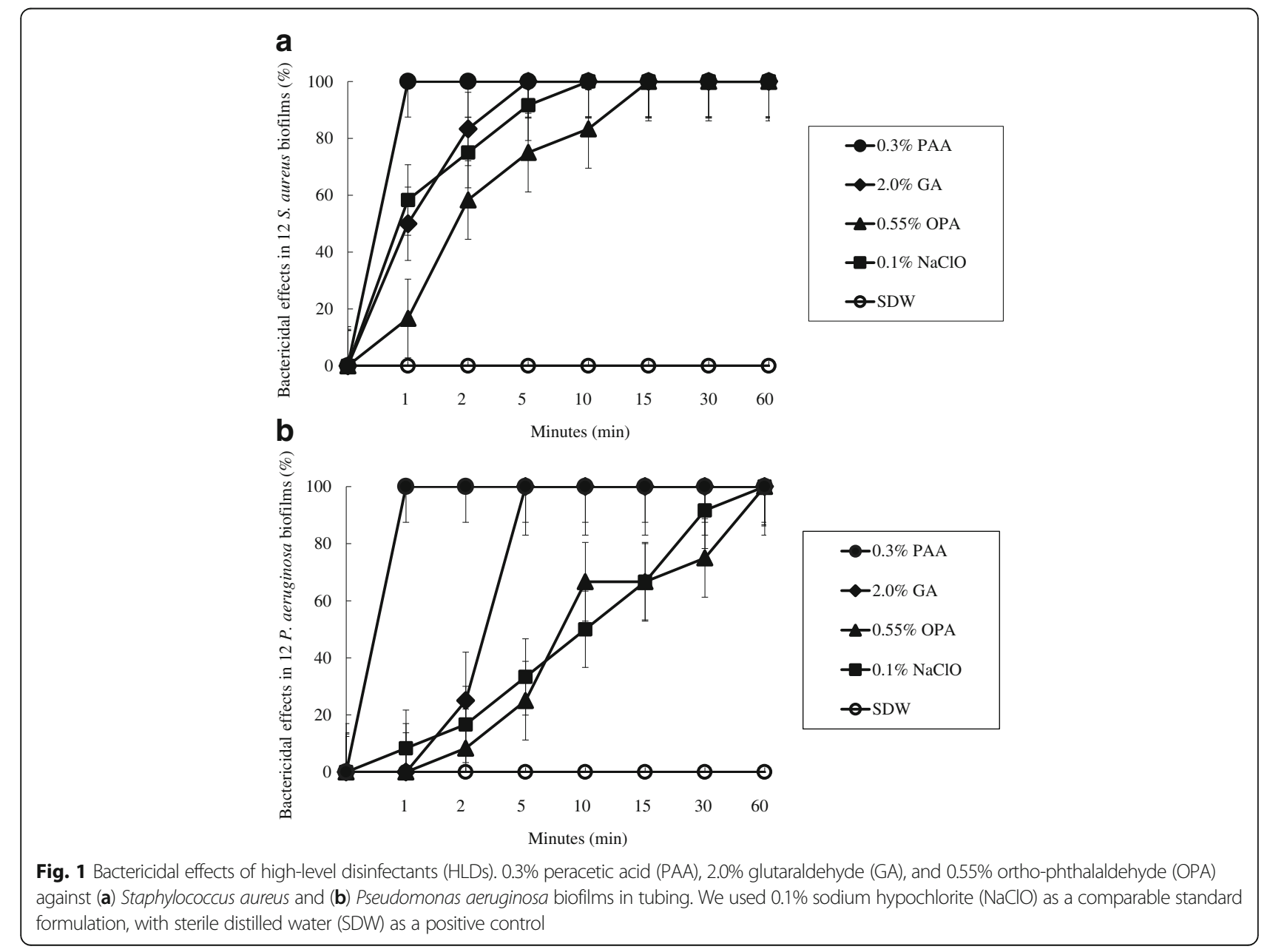


ineffective, as judged by the amount of remaining biofilm mass and weaker activity relative to that of GA $(P=0.0159)$. $P$. aeruginosa biofilm was more resistant than $S$. aureus biofilm to OPA and $\mathrm{NaClO}(P<0.01)$, whereas no significant differences were observed between biofilms treated with PAA and GA $(P=0.1846)$.

\section{Morphological observation by TEM and SEM}

The mechanisms of action of PAA and GA against $S$. aureus and $P$. aeruginosa biofilms were determined by morphological observation using TEM (Fig. 2) and SEM (Fig. 3). TEM results showed that the control biofilms were devoid of artifacts, and PAA elicited the appearance of bleb-like bulges after $5 \mathrm{~min}$ and collapsed cell structures after $30 \mathrm{~min}$. The observed differences between $S$. aureus and $P$. aeruginosa biofilms were partially based on discrepancies in bacterial structures such as the cell wall. SEM analysis showed that control biofilms presented mature surfaces devoid of brittleness, fissures, cracks, grooves, pores, erosion, pits, or peeling of the catheter surface. PAA caused cell-cortex damage after $5 \mathrm{~min}$ and cell-structure compression after $30 \mathrm{~min}$. Both TEM and SEM results indicated that GA-treated biofilms were firmly fixed. Additionally, the duration of antiseptic activity appeared similar for both $S$. aureus and $P$. aeruginosa biofilms following treatment with PAA. Notably, SEM microphotographs revealed reduced biofilm coating on catheter surfaces following treatment with PAA.

\section{Discussion}

Our study is the first to utilize TEM and SEM to document biofilm formation and investigate the bactericidal effects of PAA. Our in vitro biofilm models exhibited mature biofilm development inside a narrow catheter lumen, as reported previously, thus mimicking biofilm formation inside the endoscope channel [23]. Notably, different HLDs presented varying bactericidal effects on $S$. aureus and $P$. aeruginosa biofilms in our in vitro biofilm models. Accordingly, PAA had the most rapid bactericidal activity $(<1 \mathrm{~min})$, in line with a report by Tote et al. [24]. In contrast, OPA required $>10 \mathrm{~min}$ and 30 min to completely eradicate $S$. aureus and $P$. aeruginosa biofilms, respectively. These results indicate that $P$. aeruginosa shows reduced susceptibility to OPA due to overproduction of biofilm matrix components [25]. The

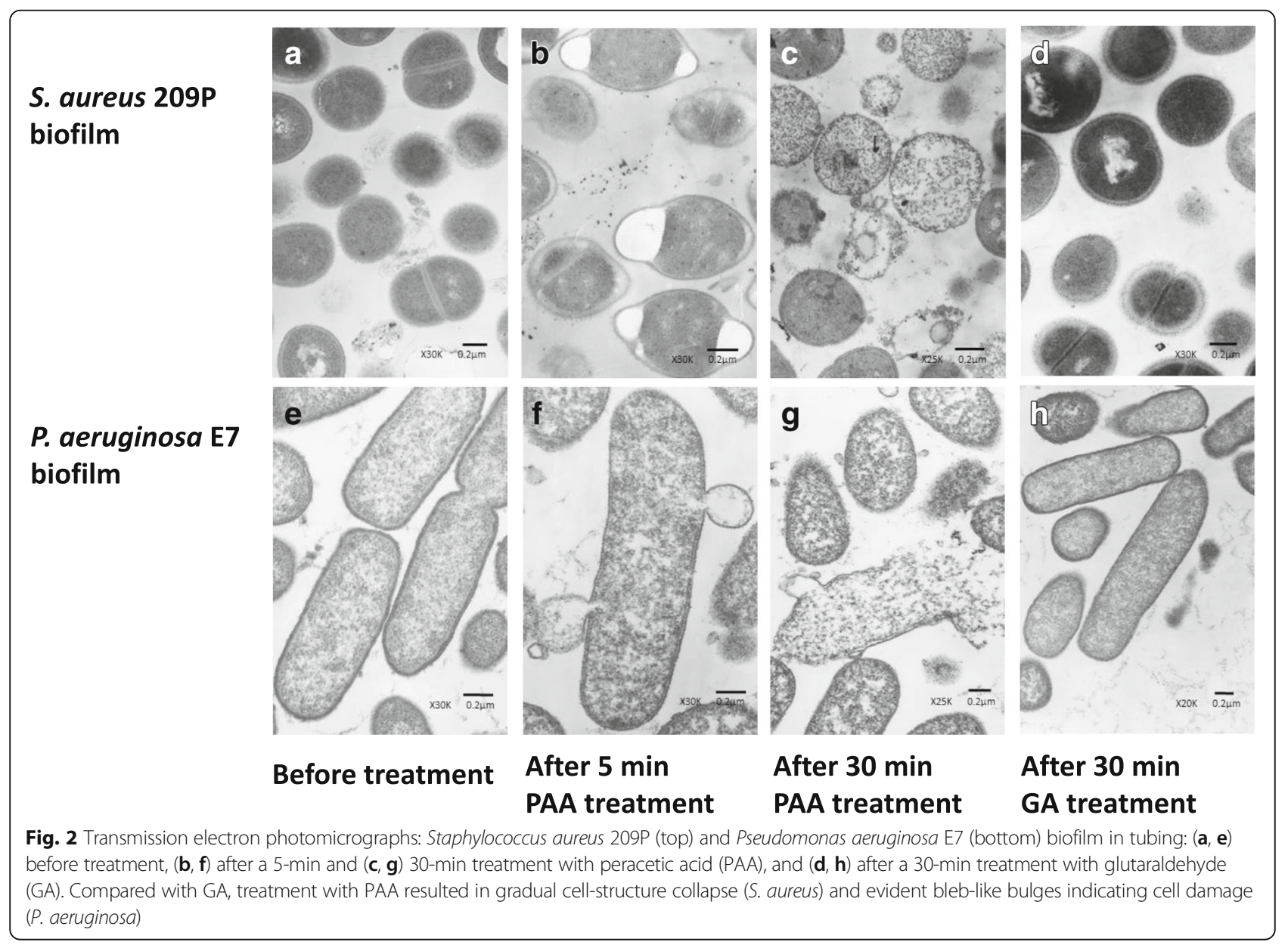




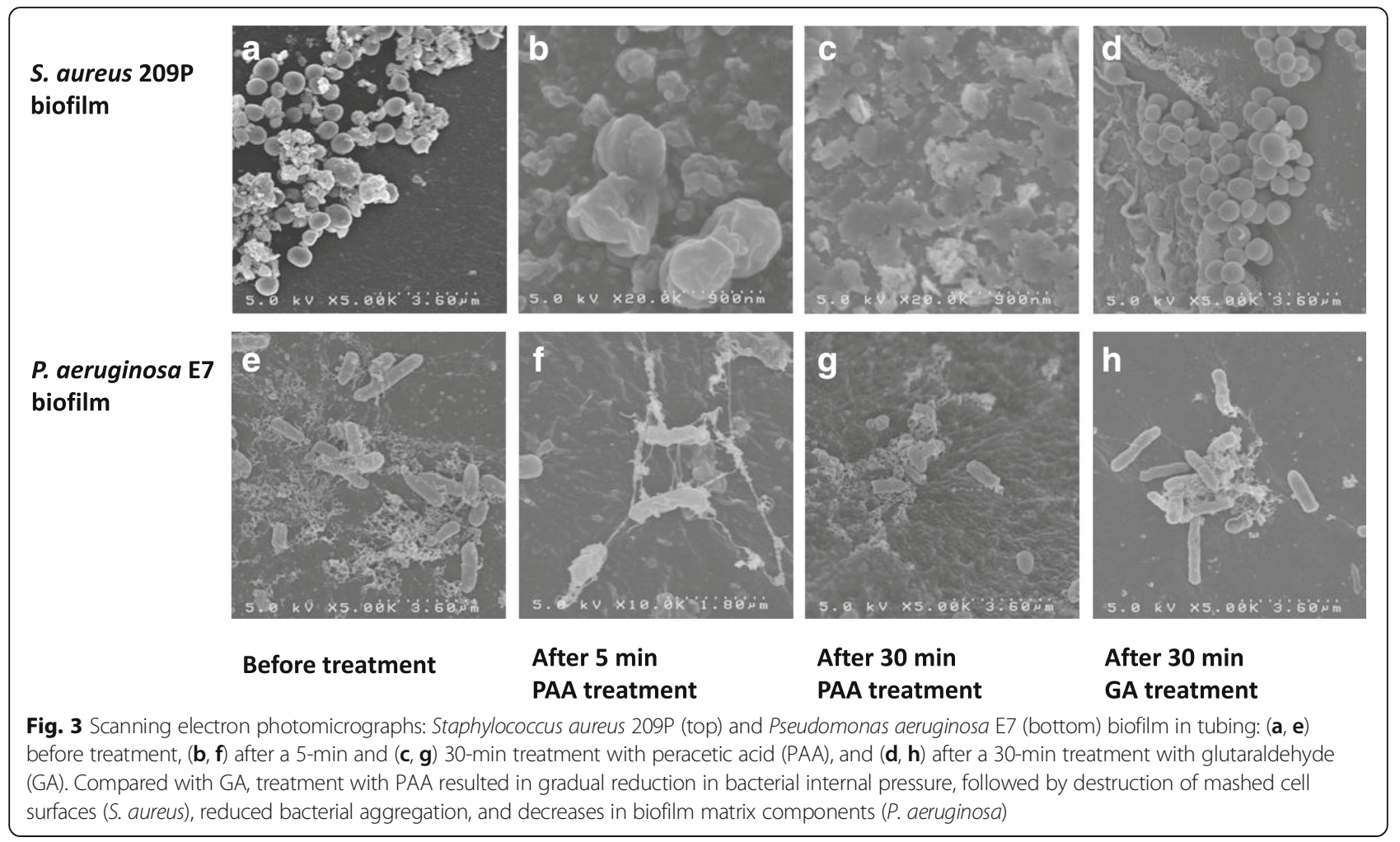

P. aeruginosa biofilm is comprised of bacteria embedded in a matrix of extracellular polymeric substances, which functions as both a structural scaffold and/or as a protective barrier against harsh environments. Alginate or other polysaccharides have been identified as the main matrix ingredients in $P$. aeruginosa biofilms, with important roles in structural maintenance and AMR [2]. Additional compounds affecting biofilm matrix and tolerance of $P$. aeruginosa biofilms to OPA are currently being investigated. Polysaccharide intercellular adhesin has also been described as a major proteinaceous component of the $S$. aureus biofilm matrix, which is also rich in teichoic acids [4]. Other cellular components are likely to be present, and await further investigation. To address a study limitation, our future work will investigate the influence of HLDs on several known biofilm matrices from other bacterial strains. However, as disinfection exposure time recommended by guidelines for endoscope reprocessing may differ by biofilm matrix, as indicated by testing OPA in this study, it would be necessary to select an HLD with stronger and fast-acting bactericidal effects, such PAA, in practical use.

Although mature $S$. aureus and $P$. aeruginosa biofilms are characterized by production of matrix components that hinder biofilm killing, PAA appears to be an effective disinfectant. TEM and SEM observations enabled a comparative analysis of the mechanism of action of PAA, revealing changes in shape after $5 \mathrm{~min}$ and structural damage after $30 \mathrm{~min}$. In the current report, mature $P$. aeruginosa biofilms aged $96 \mathrm{~h}$ were eradicated at $3000 \mathrm{ppm}(0.3 \%)$ of PAA after 5-min exposure [26]. Our findings indicate that the exposure time for effective bactericidal activity is 5 min under high concentrations of HLD, e.g., 0.3\% PAA.

These alterations might be caused by a sharp decrease in bacterial inner pressure resulting from high permeability to PAA for a short period. Additionally, PAA is thought to act as an oxidizing agent by releasing hydroxyl radicals, which subsequently attack essential biofilm matrix components [27-29]. To date, no PAAresistance mechanisms have been reported for either cell suspensions or biofilms. Here, spectroscopic measurements of bacterial survival correlated well with TEM and SEM observations of biofilm structures and surfaces. This in vitro biofilm model associated with electron microscopy represents an effective tool to investigate the mechanistic action of disinfectants such as PAA. Future work on biofilm formation should help elucidate the nature of interactions under changing environmental conditions (e.g., $\mathrm{pH}$ ) or in the presence of plasma for various durations of exposure.

In summary, we found that PAA is a useful HLD for endoscope channel reprocessing, even in the presence of strongly adhering bacterial biofilms. The current developments should allow for shorter exposure time for effective bactericidal activity during endoscope reprocessing 
in healthcare settings. This is expected to enable the prevention of endoscopy-related infections resulting from potential contamination by $S$. aureus and $P$. aeruginosa biofilms.

\section{Conclusions}

Morphological observations of in vitro biofilm models by electron microscopy showed that PAA exhibited more rapid bactericidal effects than OPA or GA against $S$. aureus and $P$. aeruginosa biofilms, which are associated with endoscopy-related infections. Therefore, these findings suggest that PAA has fast-acting effects against $S$. aureus and $P$. aeruginosa biofilms.

\section{Abbreviations}

AER: Automated endoscope reprocessor; AMR: Antimicrobial resistance; CFU: Colony-forming units; GA: Glutaraldehyde; HLD: High-level disinfection; MHB: Mueller-Hinton broth; $\mathrm{NaClO}$ : Sodium hypochlorite solution; OPA: Ortho-phthalaldehyde; PAA: Peracetic acid; PBS: Phosphate-buffered saline; SDW: Sterile distilled water; SEM: Scanning electron microscopy; TEM: Transmission electron microscopy

\section{Acknowledgments}

We thank Prof. Akiyoshi Tsuji, School of Medicine, Toho University, for providing strains and supervising the biofilm-killing experiments. We also thank Masako Hara, PhD, Ocean Research Institute, University of Tokyo, for kindly supporting all SEM observation procedures. We would like to thank Editage (https://www.editage.com/) for English language editing.

\section{Funding}

This work was supported by JSPS KAKENHI (grant 16,922,135).

\section{Availability of data and materials}

Not applicable

\section{Authors' contributions}

All authors read and approved the final manuscript.

\section{Ethics approval and consent to participate}

Not applicable

\section{Consent for publication}

Not applicable

\section{Competing interests}

The authors declare that they have no competing interests.

\section{Publisher's Note}

Springer Nature remains neutral with regard to jurisdictional claims in published maps and institutional affiliations.

\section{Author details}

'Department of Infection Control and Prevention, Medical Hospital, Tokyo Medical and Dental University, Tokyo, Japan. ${ }^{2}$ Clinical Development Department, FUJIFILM Pharma Co., Ltd, 26-30, Nishiazabu 2-Chome, Tokyo, Japan. ${ }^{3}$ Department of Molecular Pathology, Graduate School of Medicine, The University of Tokyo, Tokyo, Japan. ${ }^{4}$ Department of Infection Control and Prevention, The University of Tokyo Hospital, Tokyo, Japan.

Received: 14 August 2017 Accepted: 23 November 2017

Published online: 01 December 2017

\section{References}

1. Costerton JW. The etiology and persistence of cryptic bacterial infections: a hypothesis. Rev Infect Dis. 1984;6:S608-16.

2. Wei $Q, M a ~ L Z$. Biofilm matrix and its regulation in Pseudomonas aeruginosa. Int J Mol Sci. 2013;14:20983-1005.
3. Fong JN, Yildiz FH. Biofilm matrix proteins. Microbiol Spectr. 2015;3:1-27.

4. Paharik $A E$, Horswill AR. The staphylococcal biofilm: adhesins, regulation, and host response. Microbiol Spectr. 2016;4:1-48.

5. Pajkos A, Vickery $\mathrm{K}$, Cossart Yl. Biofilm accumulation on endoscope tubing a contributor to the failure of cleaning and decontamination? J Hosp Infect. 2004:58:224-9.

6. Qiu L, Zhou Z, Liu Q, Ni Y, Zhao F, Cheng H. Investigating the failure of repeated standard cleaning and disinfection of a Pseudomonas aeruginosainfected pancreatic and biliary endoscope. Am J Infect Control. 2015;43:e43-6.

7. Ofstead $\mathrm{CL}$, Wetzler HP, Doyle EM, Rocco CK, Visrodia KH, Baron TH, et al. Persistent contamination on colonoscopes and gastroscopes detected by biologic cultures and rapid indicators despite reprocessing performed in accordance with guidelines. Am J Infect Control. 2015;43:794-801.

8. Brandabur JJ, Leggett JE, Wang L, Bartles RL, Baxter L, Diaz GA, et al. Surveillance of guideline practices for duodenoscope and linear echoendoscope reprocessing in a large healthcare system. Gastrointest Endosc. 2016:84:392-9.

9. Kirschke DL, Jones TF, Craig AS, Chu PS, Mayenick GG, Patel JA, et al. Pseudomonas aeruginosa and Serratia marcescens contamination associated with a manufacturing defect in bronchoscopes. N Engl J Med. 2003;348:214-20.

10. Kovaleva J, Degener JE, van der Mei HC. Mimicking disinfection and drying of biofilms in contaminated endoscopes. J Hosp Infect. 2010;76:345-50.

11. Ren-Pei W, Hui-Jun X, Ke Q, Dong W, Xing N, Zhao-Shen L. Correlation between the growth of bacterial biofilm in flexible endoscopes and endoscope reprocessing methods. Am J Infect Control. 2014;42:1203-6.

12. Griffiths PA, Babb JR, Bradley CR, Fraise AP. Glutaraldehyde-resistant Mycobacterium chelonae from endoscope washer disinfectors. J Appl Microbiol. 1997:82:519-26.

13. Tschudin-Sutter S, Frei R, Kampf G, Tamm M, Pflimlin E, Battegay M, et al. Emergence of glutaraldehyde-resistant Pseudomonas aeruginosa. Infect Control Hosp Epidemiol. 2011;32:1173-8.

14. Lorena NS, Pitombo MB, Côrtes PB, Maya MC, Silva MG, Carvalho AC, et al. Mycobacterium massiliense BRA100 strain recovered from postsurgical infections: resistance to high concentrations of glutaraldehyde and alternative solutions for high level disinfection. Acta Cir Bras. 2010;25:455-9.

15. Bridier A, Briandet R, Thomas V, Dubois-Brissonnet F. Comparative biocidal activity of peracetic acid, benzalkonium chloride and ortho-phthalaldehyde on 77 bacterial strains. J Hosp Infect. 2011;78:208-13.

16. Neves MS, da Silva MG, Ventura GM, Côrtes PB, Duarte RS, de Souza HS. Effectiveness of current disinfection procedures against biofilm on contaminated Gl endoscopes. Gastrointest Endosc. 2016;83:944-53.

17. Rutala WA, Weber DJ. Guideline for disinfection and sterilization in healthcare facilities, 2008. Atlanta: Centers for Disease Control; 2008.

18. Petersen BT, Chennat J, Cohen J, Cotton PB, Greenwald DA, Kowalski TE, et al. Multisociety guideline on reprocessing flexible Gl endoscopes: 2011. Infect Control Hosp Epidemiol. 2011;32:527-37.

19. SGNA Practice. Committee 2013-14. Guideline for use of high-level disinfectants and sterilants for reprocessing flexible gastrointestinal endoscopes. Gastroenterol Nurs. 2015:38:70-80.

20. Simões $M$, Carvalho $H$, Pereira MO, Vieira MJ. Studies on the behaviour of Pseudomonas fluorescens biofilms after Ortho-phthalaldehyde treatment. Biofouling. 2003;19:151-7.

21. Simões $M$, Simões LC, Cleto S, Machado I, Pereira MO, Vieira MJ. Antimicrobial mechanisms of ortho-phthalaldehyde action. J Basic Microbiol. 2007:47:230-42.

22. Vikram A, Bomberger JM, Biddy KJ. Efflux as a glutalaldehyde resistance mechanism in Pseudomonas fluorescens and Pseudomonas aeruginosa biofilms. Antimicrob Agents Chemother. 2015;59:3433-40.

23. Rodrigo CS, Ryan AC, Carolyn PO, Patrick JA. Efficacy of disinfecting solutions in removing biofilms from polyvinyl chloride tracheostomy tubes. Laryngoscope. 2013;123:259-63.

24. Tote K, Horemans T, Vanden Berghe D, Maes L, Cos P. Inhibitory effect of biocides on the viable masses and matrices of Staphylococcus aureus and Pseudomonas aeruginosa biofilms. Appl Environment Microbiol. 2010;76:3135-42.

25. Simões $M$, Pereira MO, Vieira MJ. Effect of different concentrations of orthophthalaldehyde on biofilms formed by Pseudomonas fluorescens under different flow conditions. Biofouling. 2003;19:287-95.

26. Akinbobola AB, Sherry L, Mckay WG, Ramage G, Williams C. Tolerance of Pseudomonas aeruginosa in in-vitro biofilms to high-level peracetic acid disinfection. J Hosp Infect. 2017;97:162-8. 
27. Rutala WA, Weber DJ. Disinfection of endoscopes: review of new chemical sterilants used for high-level disinfection. Infect Control Hosp Epidemiol. 1999;20:69-76

28. Toté K, Berghe DV, Deschacht M, de Wit K, Maes L, Cos P. Inhibitory efficacy of various antibiotics on matrix and viable mass of Staphylococcus aureus and Pseudomonas aeruginosa biofilms. Int J Antimicrob Agents. 2009;33:525-31.

29. Chenjiao W, Hongyan Z, Qing G, Xiaogi Z, Liying G, Ying F. In-use evaluation of peracetic acid for high-level disinfection of endoscopes. Gastroenterol Nurs. 2016:39:116-20.

Submit your next manuscript to BioMed Central and we will help you at every step:

- We accept pre-submission inquiries

- Our selector tool helps you to find the most relevant journal

- We provide round the clock customer support

- Convenient online submission

- Thorough peer review

- Inclusion in PubMed and all major indexing services

- Maximum visibility for your research

Submit your manuscript at www.biomedcentral.com/submit
Biomed Central 